Journal of Engineering and Applied Sciences 14 (Special Issue 3): 5985-5992, 2019

ISSN: 1816-949X

(C) Medwell Journals, 2019

\title{
Effect of Gravity, Side Pressure and Direct Force on the Free Vibration Characteristics of Cantilever Plate
}

\author{
Iesam Jondi Hasan \\ Department of Refrigeration and Air-Conditioning Engineering, Technical College, \\ Northern Technical University, Mosul, Kirkuk, Iraq \\ iesamjondi72@yahoo.com
}

\begin{abstract}
This study aims to analyze the vibration characteristics for cantilever plate under pre-stresses. The effect of gravity (self-weight) of cantilever plate, side fluid pressure with different immersed ratios and direct tensile and compressive force are taken into account. The natural frequencies and mode shapes are obtained with and without the pre-stresses. The effect of gravity was studied during $\left(180^{\circ}\right)$ angle of support starting from vertical downward support to vertical upward support. Then the effect of side fluid pressure was studied for fully, partially and non-immersed cases. Also, the effect of direct tensile and compressive forces acting at the tip of the plate in the direction parallel to the plate axis, was studied to find the effect of the force on the natural frequencies. The numerical Finite Element Method (FEM) is used in the analyses by using the ANSYS Workbench Software using the interaction between (structural static) and (modal) analysis. Two plates with different material are used in the study with the same geometry as a uniform rectangular plate to analyses the gravity and side fluid pressure effects and only one plate used to analyses the direct force effect. For the self-weight problem, the tension effect tends to increase the natural frequencies but the compression effect tends to decrease the natural frequencies because of the buckling tendency and in the case of pure bending which means that the tension at the upper surface and compression at the lower surface are equals, the natural frequencies remain the same as in the case of no gravity effect. For the side fluid pressure problem, the contact with fluid tends to decrease the natural frequencies. Then for the direct force cases in the tensile case the natural frequencies were increasing and in the compressive case, the natural frequencies were decreasing. For all cases, the mode shapes still the same with and without pre-stresses. All results compared with the results without pre-stresses.
\end{abstract}

Key words: Cantilever plate, natural frequencies, pre-stresses effect, gravity, fluid tends, compression

\section{INTRODUCTION}

Plates are widely used in engineering structural components, like in cars, ships, pressure vessels, turbines blade and other structural components. Such structures are subjected to various external forces. Among them, pressure, temperature force, self-weight, etc. These quasi-static loads yield initial stress (pre-stress) effects which change the plate characteristics, especially the dynamic (vibration) characteristics. Structural dynamics behavior is widely studied under the effect of the pre-stress, like the direct stress, fluid contact stress, thermal stress, dead weight etc. These studies aim to investigate, improving or controlling the vibration characteristics especially the natural frequencies and mode shapes.

Dynamic vibratory analysis of beam under purely axial pre-stress has attention in the literature (Bokaian, 1988, 1990; Abramovich, 1992), for example. It is known that the natural frequencies for transverse vibration usually increasing in pure tensile stress and decreasing in pure compressive stress, especially for lower frequencies and these effects are decreasing with high frequencies. For vertical supporting beams under gravity effect where the load purely axial though not constant, some linear analysis can be found by Yokoyama (1990) and Abramovich (1993). The natural frequencies of cantilever beams was investigated for statically deformed beams and compared with the curved beams that have the same initial curved shape without forced deflection which found that each beam has different frequencies and there is not any general relationship between them where there are differences between the natural frequencies of the forced deformed beam and natural frequencies of curved shape beam as by Cornil et al. (2007). The exact solution of natural frequencies for cantilever beams with a mass at the tip and slender in the axial direction by Lajimi and Heppler (2012). 
The objective of present paper are study the effect of gravity, side pressure due to the contact with fluid and direct tensile and compressive forces on the natural frequencies and mode shapes of thin cantilever plate using the Finite Element Method (FEM) by ANSYS Workbench Software by using the interaction technique between the static structural analysis and modal analysis.

\section{MATERIALS AND METHODS}

Dynamic analysis of thin cantilever plate using FEM: The thin plate with simple geometry which has two flat surfaces parallel to each other analyzed by classical Kirchhoff's theory which assumed that the displacements are small compared with thickness, the normal stress to the mid-surface of the plate and the transverse shear stresses are negligible, the mid-surface of the plate is neutral surface during bending and normal to the mid-surface before deformation remain straight and normal after deformation. By using the numerical analysis of (FEM) with Kirchhoff's 3D element the plate domain discretization to sub-domains, this sub-domains have rectangular or triangular shapes with some nodes in certain positions, each node have three degrees of freedom, one linear normal to the element $(\omega)$ and two angulars $\left(\theta_{\mathrm{x}}\right.$ and $\left.\theta_{\mathrm{y}}\right)$ about $\mathrm{x}$ and $\mathrm{y}$-axis, respectively. And due to the bending behavior, the element subjected to three loads type, one shear force in the z-direction and two bending moments in the $\mathrm{x}$ and $\mathrm{y}$-direction (Leissa, 1969; Werner, 2004; Seshu, 2012).

To use the (FEM) there are some different elements using to discretization the plate domain, a rectangular element with corner nodes, a rectangular element with corner and mid-line nodes, a triangular element with corner nodes and triangular element with corner mid-line nodes. By expressing the strain $(\epsilon)$ and stress $(\sigma)$ at any point in terms of nodal displacements and shape functions as shown in the Eq. 1:

$$
\in=\left[\begin{array}{c}
\epsilon_{\mathrm{x}} \\
\epsilon_{\mathrm{y}} \\
\gamma_{\mathrm{xy}}
\end{array}\right], \quad \sigma=\left[\begin{array}{c}
\sigma_{\mathrm{x}} \\
\sigma_{\mathrm{y}} \\
\tau_{\mathrm{xy}}
\end{array}\right]
$$

The total potential energy equal to:

$$
\mathrm{X}=\mathrm{U}-\mathrm{W}=\frac{1}{2} \delta^{\mathrm{t}}\left[\iiint \mathrm{B}^{\mathrm{t}} \cdot \mathrm{D} \cdot \mathrm{B} \cdot \mathrm{dxdydz}\right] \delta-\delta^{\mathrm{t}} \mathrm{F}
$$

Where:

$\mathrm{U}=$ The strain energy and

$\mathrm{W}=$ The internal force energy

For the isotropic, linear strain and homogeneous materials the $\mathrm{D}$ equal to:

$$
\mathrm{D}=\frac{\mathrm{E}}{1-v^{2}}\left[\begin{array}{ccc}
1 & v & 0 \\
v & 1 & 0 \\
0 & 0 & \frac{1-v}{2}
\end{array}\right]
$$

By using the minimization of $\mathrm{X}$, the stiffness matrix can be expressed as:

$$
[K]=\iint B^{t} \cdot D \cdot B \cdot d x d y
$$

And from dynamics equations of the structure the mass matrix can be expressed as:

$$
[\mathrm{M}]=\iint \rho \cdot \mathrm{N}^{\mathrm{t}} \cdot \mathrm{N} \cdot \mathrm{dxdy}
$$

where, $(N)$ is the shape functions matrix for each element. For each element the stiffness and mass matrices must be formulated and to solve the dynamics plate problems its need to summation the discretization element by adding the contact nodes matrices between each neighboring elements, then the overall matrices using in the general equation of dynamic behavior as shown in the Eq. 6 :

$$
\left\{[\mathrm{K}]-\omega^{2}[\mathrm{M}]\right\}\{\delta\}=\{0\}
$$

Where:

$[\mathrm{K}]=$ The global stiffness matrix

$[\mathrm{M}]=$ The global mass matrix

$\{\mathrm{M}\}=$ The vectors containing the nodes behavior

$\{\delta\}=$ The natural frequency

Pre-stresses plate simulation using FEM: When the plate subjects to a pre-stress due to certain effects like gravity, pressure or force, then the finite element matrices was changing by adding the pre-stress effect on the matrices. These effects were adding to the mass matrix as adding mass matrix $[\mathrm{m}]$. The adding mass matrix can be forming as a lumped mass matrix, pressure matrix or force matrix. Then the Eq. 7 of motion became as:

$$
\left\{[\mathrm{K}]-\omega^{2}[\mathrm{M}+\mathrm{m}]\right\}\{\delta\}=\{0\}
$$

In general, the size of these matrices is large and the solving of the problem is very difficult by hand, especially when taking the external effect in the account. Therefore, the using of the computer software is very important to reduce the racket and time to solve the problems. 
Pre-stressed plate simulation by ANSYS Software: In the case of the pre-stressed plate, there are two types of simulation in ANSYS Workbench must be used to analyze the plating behavior, static structural analysis and modal analysis as shown in Fig. 1. The static structural analysis using to analyze the effect of the static loads on the plate due to forces, moments, pressures, etc. and the modal analysis using to analyze the free vibration behavior of the plate and to find the free vibration characteristics of the plate.

The ANSYS Workbench Software gives the ability to produce interactions between two or more types of analyses as one or two ways. In the case of static structural and modal analysis it can be directly interaction in one way from static structural results to modal analysis simulation only as represent in Fig. 2 where the results of the loads on the plate as pre-stresses in static

Table 1: Dimensions and mechanical properties of plates

\begin{tabular}{lll}
\hline Dimensions and properties & Structural steel plate & Copper alloy plate \\
\hline Length $(\mathrm{L})(\mathrm{m})$ & 1 & 1 \\
Width $(\mathrm{W})(\mathrm{m})$ & 0.2 & 0.2 \\
Thickness $(\mathrm{t})(\mathrm{m})$ & 0.005 & 0.005 \\
Modulus of Elasticity $(\mathrm{E})(\mathrm{GPa})$ & 200 & 110 \\
Density $(\rho)\left(\mathrm{kg} / \mathrm{m}^{3}\right)$ & 7830 & 8300 \\
Poisson's ratio $(\mathrm{v})$ & 0.3 & 0.34 \\
\hline
\end{tabular}
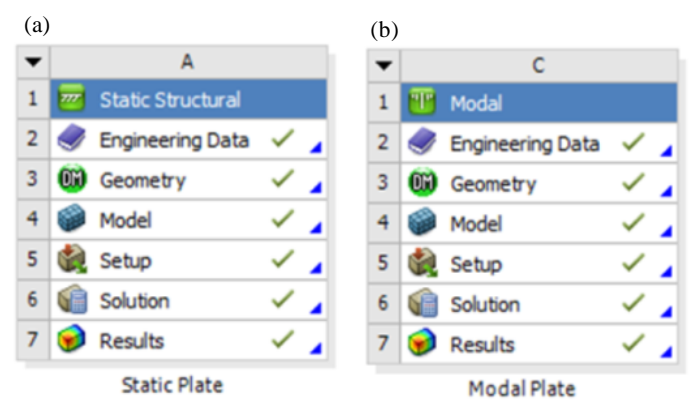

Fig. 1: Static strutural and modal analysis of plate in ANSYS workbench condition can be transforming to the modal analysis as shown in the project tree which can be used to find the effect of these pre-stresses on the dynamic characteristics. In the present thesis, the deflections and stresses as a result of static loads due to self-weight of the cantilever plate by the gravity, the pressure of the contact fluid on the immersed part of the plate and direct tension and compression forces on the plate end are investigated. These results transformed to the modal analysis to estimate the effect of the static analysis of the dynamic analysis.

Effect of pre-stresses on the free vibration characteristics of cantilever plate: To study the effect of pre-stresses on the vibration behavior of a cantilever plate, two rectangular plates with different material was used. The two plates are of structural steel and copper alloys, respectively with mechanical properties and dimensions as given in Table 1 are used.

Effect of gravity on the free natural frequency of cantilever plate: In this case, the cantilever plate places in different angles started from the vertically downward position and finished on the vertically upward position or for $\left(180^{\circ}\right)$ with $\left(10^{\circ}\right)$ for each step as shown in Fig. 3. At first by static structural analysis, the bending, tensile and compressive behaviors of the plate under the gravity effect for each angle will be investigated and then these behavior results transferred to the modal analysis and calculated the effect of these results on the natural frequencies of the plates.

Effect of side fluid pressure on the free natural frequency of cantilever plate: In this case, the same two plates of the previous study are used but with a case of vertical cantilever plate downward only immersed in water with five immersed ratios $(d / L)$ as $(0.2,0.4,0.6,0.8$ and 1.0$)$, respectively as shown in the Fig. 4. At first by static
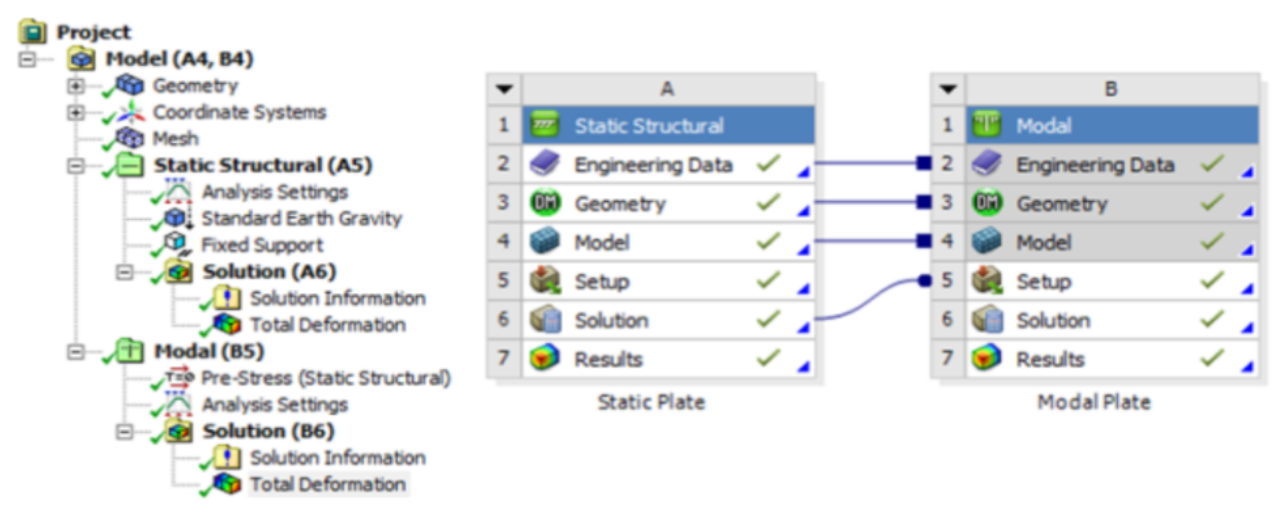

Fig. 2: One-way interaction static structural and modal analysis by ANSYS workbench 


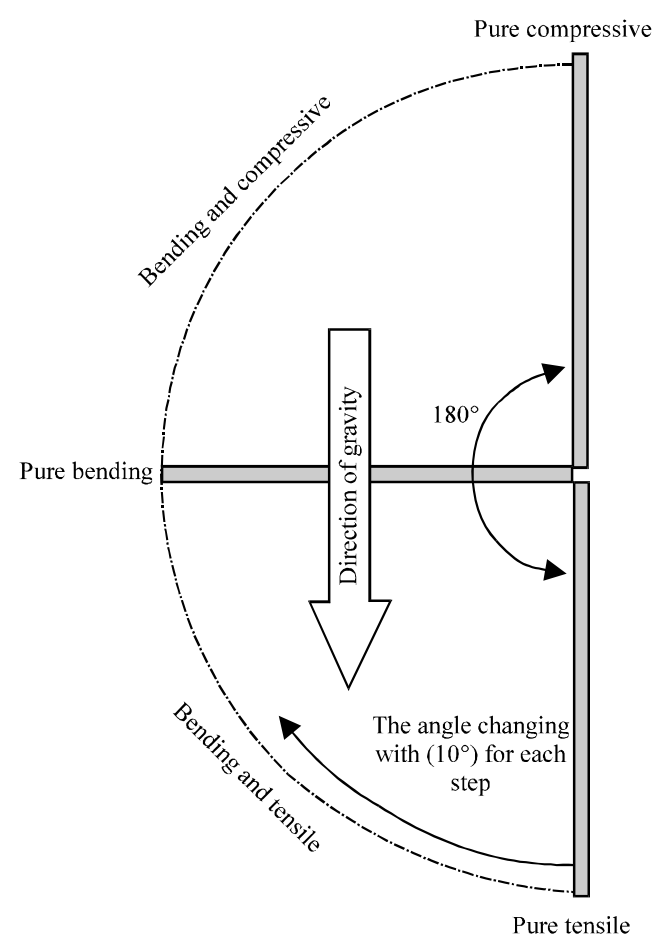

Fig. 3: The cantilever plate supports with different angle under gravity effect

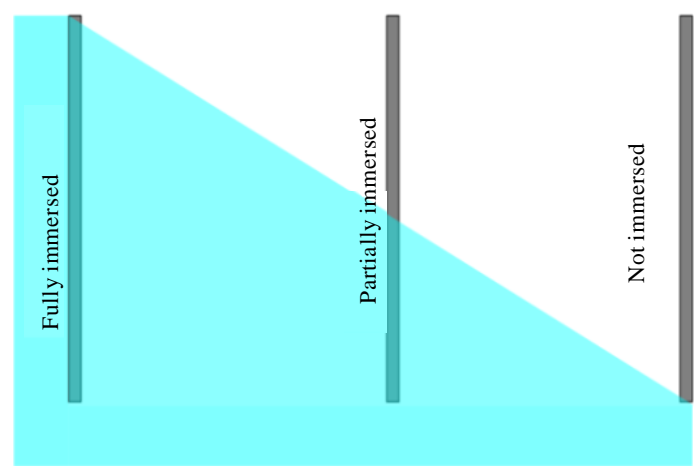

Fig. 4: Centilever plate supports vertically immersed in fluid structural analysis, the pre-stress of the plate under the effect of water pressure was investigated and then, these stresses results transferred to the modal analysis and calculated the effect of these results on the natural frequencies of the plates.

Effect of direct axial forces on the free natural frequency of cantilever plate: In this case, the same structural steel plate only of the previous study are used but with a case of applying direct axial tensile and compressive forces on the tip of the plate. The force value changed from $(0-800 \mathrm{~N})$ increasing by $(200 \mathrm{~N})$, after that the pre-tensile stresses and pre-compressive stresses induced on the plate transferred to the modal analysis and investigate the effect of this loads on the natural frequencies of the plate.

\section{RESULTS AND DISCUSSION}

The natural frequencies and mode shapes for the plates were investigated before and after the pre-stresses induced by the gravity effect, contact fluid pressure and from the direct axial force on the cantilever plate tip.

Effect of gravity results: The effect of gravity with a different angle of the two cantilever plate support on the first three natural frequencies was investigated as shown in Table 2 and 3 and the relationships between the first three natural frequencies and the supporting angle are shown in Fig. 5.

The frequencies increased for tensile stresses and decreased for compressive stresses, especially for low frequencies but still constant for pure bending stress. Also, the effects of gravity on bending modes are more than on torsion modes. For structural steel plate, from supporting angle between $\left(0^{\circ}-180^{\circ}\right)$, the first three frequencies changed by $(1.3375,0.18831$ and $0.01456 \%)$, respectively where the frequencies increased by $(0.1973$,

Table 2: Changing of the first three natural frequencies for structural steel plate

\begin{tabular}{|c|c|c|c|c|c|c|c|}
\hline \multirow[b]{2}{*}{ Angle $\left({ }^{\circ}\right)$} & \multicolumn{3}{|c|}{ Natural frequency $(\mathrm{Hz})$} & \multirow[b]{2}{*}{ Angle $\left({ }^{\circ}\right)$} & \multicolumn{3}{|c|}{ Natural frequency $(\mathrm{Hz})$} \\
\hline & Mode 1 & Mode 2 & Mode 3 & & Mode 1 & Mode 2 & Mode 3 \\
\hline No gravity effect & 4.1562 & 26.014 & 41.196 & 90 & 4.1562 & 26.014 & 41.196 \\
\hline 0 & 4.2032 & 26.055 & 41.201 & 100 & 4.1480 & 26.006 & 41.195 \\
\hline 10 & 4.2025 & 26.054 & 41.201 & 110 & 4.1400 & 25.999 & 41.195 \\
\hline 20 & 4.2003 & 26.052 & 41.201 & 120 & 4.1325 & 25.993 & 41.194 \\
\hline 30 & 4.1969 & 26.049 & 41.201 & 130 & 4.1257 & 25.987 & 41.193 \\
\hline 40 & 4.1922 & 26.045 & 41.200 & 140 & 4.1199 & 25.982 & 41.192 \\
\hline 50 & 4.1865 & 26.040 & 41.200 & 150 & 4.1151 & 25.978 & 41.192 \\
\hline 60 & 4.1798 & 26.034 & 41.199 & 160 & 4.1116 & 25.975 & 41.191 \\
\hline 70 & 4.1723 & 26.028 & 41.198 & 170 & 4.1094 & 25.973 & 41.191 \\
\hline 80 & 4.1644 & 26.021 & 41.197 & 180 & 4.1087 & 25.972 & 41.191 \\
\hline
\end{tabular}


Table 3: Changing of the first three natural frequencies for copper alloy plate

\begin{tabular}{|c|c|c|c|c|c|c|c|}
\hline \multirow[b]{2}{*}{ Angle $\left({ }^{\circ}\right)$} & \multicolumn{3}{|c|}{ Natural frequency $(\mathrm{Hz})$} & \multirow[b]{2}{*}{ Angle $\left({ }^{\circ}\right)$} & \multicolumn{3}{|c|}{ Natural frequency $(\mathrm{Hz})$} \\
\hline & Mode 1 & Mode 2 & Mode 3 & & Mode 1 & Mode 2 & Mode 3 \\
\hline No gravity effect & 3.0115 & 18.844 & 29.311 & 90 & 3.0115 & 18.844 & 29.311 \\
\hline 0 & 3.0761 & 18.901 & 29.318 & 100 & 3.0002 & 18.834 & 29.309 \\
\hline 10 & 3.0752 & 18.900 & 29.318 & 110 & 2.9891 & 18.825 & 29.308 \\
\hline 20 & 3.0723 & 18.898 & 29.317 & 120 & 2.9787 & 18.815 & 29.307 \\
\hline 30 & 3.0676 & 18.894 & 29.317 & 130 & 2.9692 & 18.807 & 29.306 \\
\hline 40 & 3.0611 & 18.888 & 29.316 & 140 & 2.9611 & 18.800 & 29.305 \\
\hline 50 & 3.0532 & 18.881 & 29.315 & 150 & 2.9544 & 18.795 & 29.304 \\
\hline 60 & 3.0440 & 18.873 & 29.314 & 160 & 2.9495 & 18.79 & 29.304 \\
\hline 70 & 3.0338 & 18.864 & 29.313 & 170 & 2.9465 & 18.788 & 29.303 \\
\hline 80 & 3.0228 & 18.854 & 29.312 & 180 & 2.9455 & 18.787 & 29.303 \\
\hline
\end{tabular}
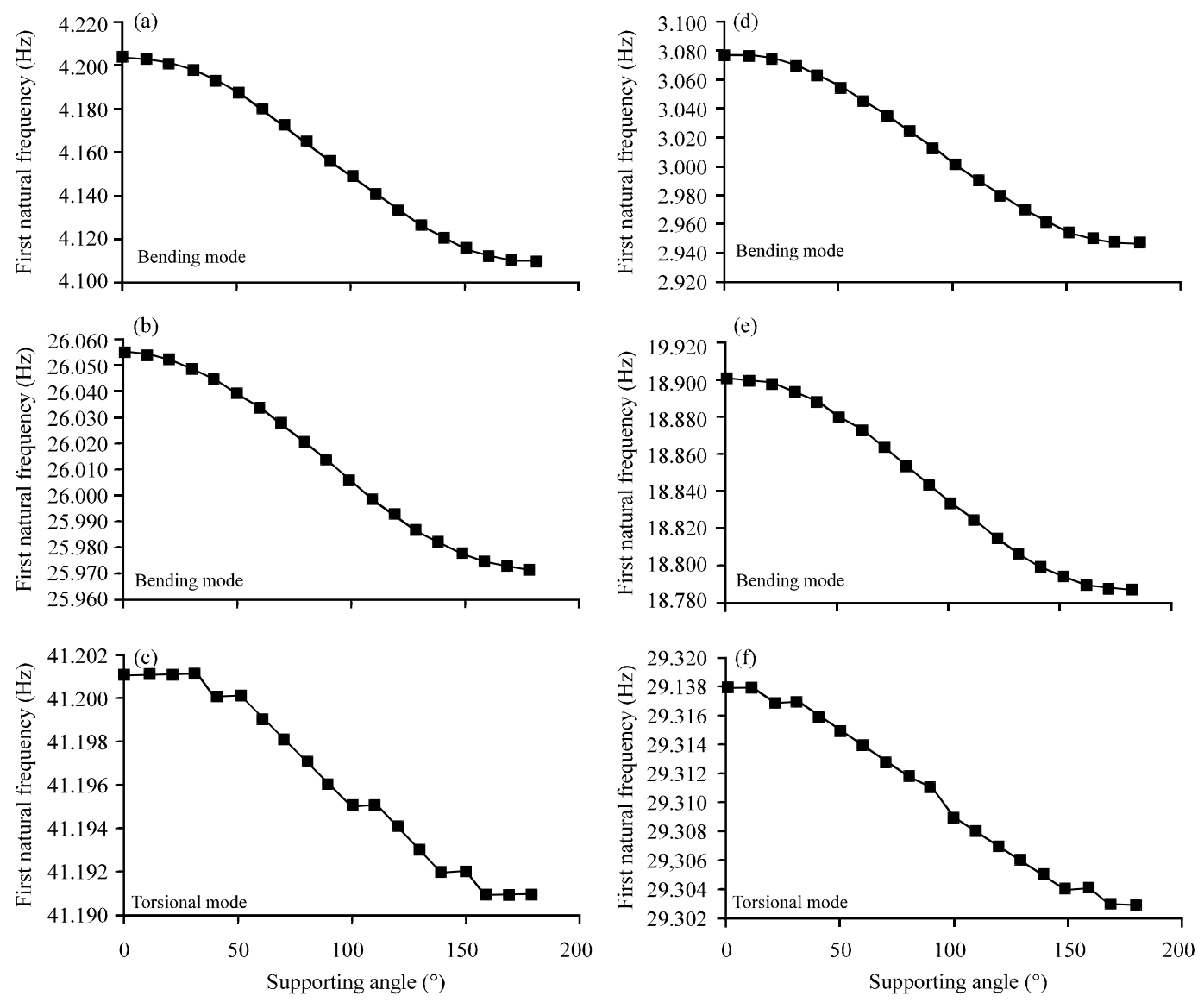

Fig. 5: The changing of first three natural frequencies with supports angle; a-c) Structural steel (left) and d-f) Copper alloy (right)

0.02691 and $0.00243 \%$ ) from pure bending to pure tensile and decreased by $(1.143,0.1615$ and $0.01214 \%)$ from pure bending to pure compressive. And for copper alloy plate, from supporting angle between $\left(0^{\circ}-180^{\circ}\right)$, the first three frequencies changed by $(2.557,0.3554$ and $0.0307 \%)$, respectively where the frequencies increased by $(0.375$, 0.0531 and $0.00341 \%$ ) from pure bending to pure tensile and decreased by $(2.192,0.3025$ and $0.0273 \%)$ from pure bending to pure compressive. For both plates, the mode shapes unchanged and remain as (bending, bending and torsion modes) with and without gravity effect.

Effect of side fluid pressure results: The effect of gravity with a different angle of the two cantilever plate support on the first three natural frequencies was investigated 


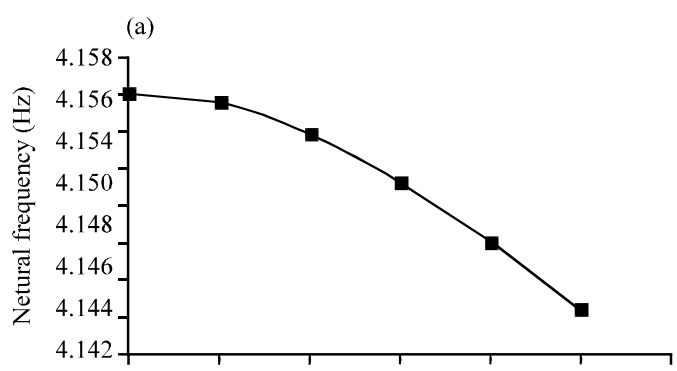

(b)
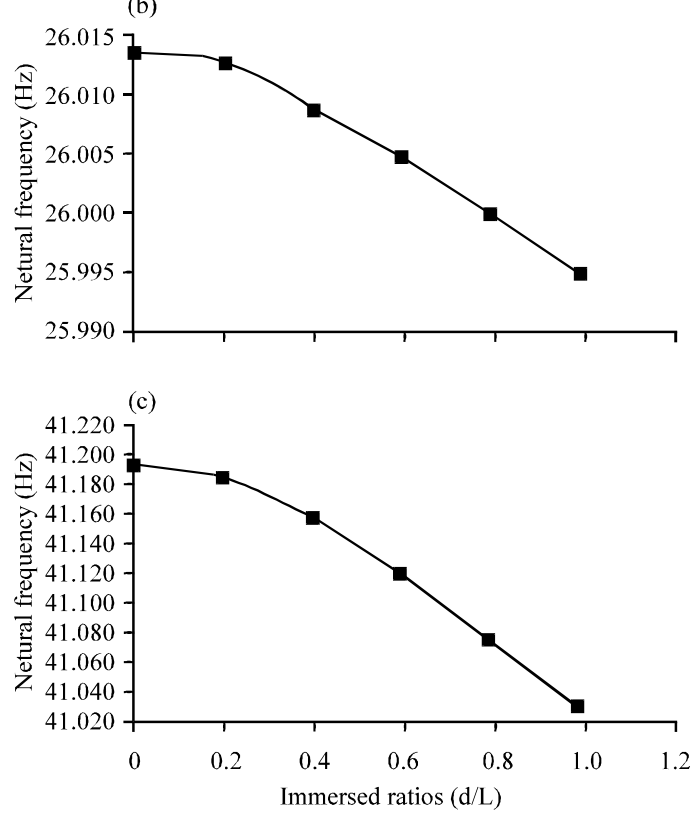

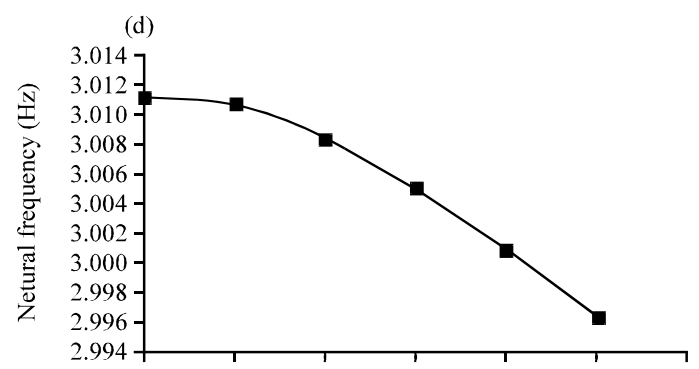

(e)
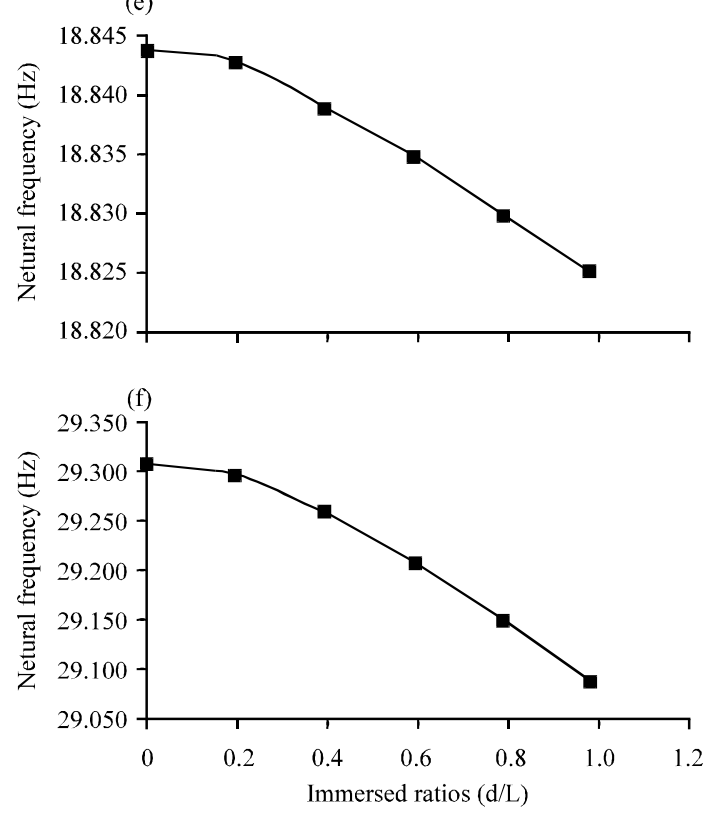

Fig. 6: The changing of first three natural frequencies with supports angle; a-c) Structural steel (left) and d-f) Copper alloy (right)

and the relationship between the first three natural frequencies and the immersed ratios represented in Fig. 6.

The frequencies decreased with increasing of the immersed ratios, especially for low frequencies and the torsion mode decreased more than bending mode. For structural steel plate, the first three natural frequencies decreased by $(0.28632,0.2114$ and $0.403 \%)$. For copper alloy plate, the first three natural frequencies decreased by $(0.5811,0.101$ and $0.757 \%)$. The mode shapes still the same with increasing the immersed ratios.

Effect of direct tensile and compressive force results: The effect of direct tensile and compressive force on the cantilever structural steel plate on the first three natural frequencies was investigated by using direct force parallel to the platesurface and applying on the plate tip with value between $(0-800 \mathrm{~N})$ by step of $(200 \mathrm{~N})$ for each reading. The relationship between the tensile and compressive forces and the first three natural frequencies for structural steel plate shown in Fig. 7.

The direct tensile stress is increasing the frequencies and the direct compressive stress is decreasing the frequencies, especially in low frequencies and bending modes. The first three natural frequencies increased by $(29.43,6.062$ and $0.1966 \%)$, respectively for tensile stress and decreased by $(49.74,6.512$ and $0.197 \%)$, respectively for compressive stress. The effect of direct compressive is more than the direct tensile stress where the compressive stress tends to buckle the plate which causing to vibrate the plate early. In all studying cases, the first three mode shapes are the same. Where the first two modes are bending mode and the third one is torsion mode as shown in Fig. 8 . 

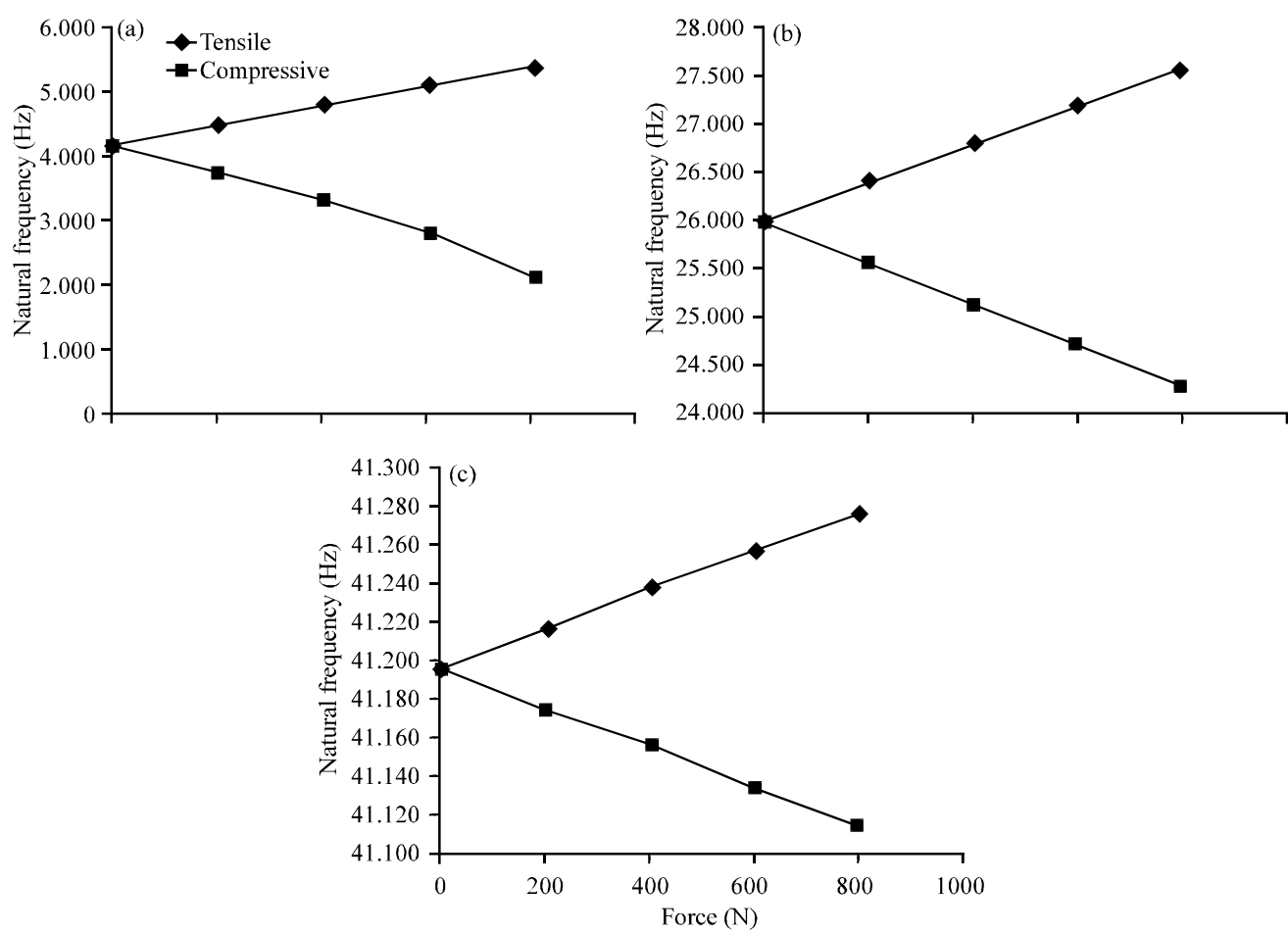

Fig. 7: Changing of natural frequencies with force; a-c) First-third frequencies changing with force

(a)

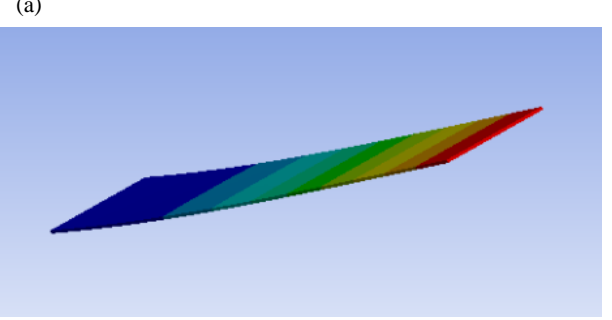

(c)

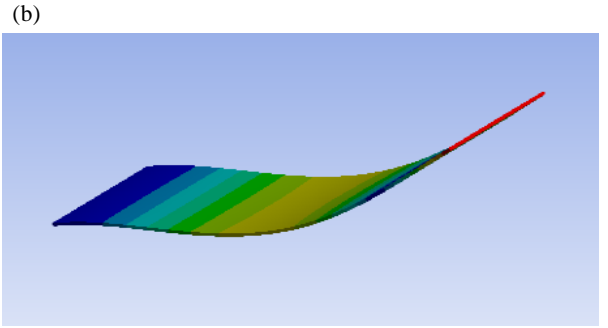

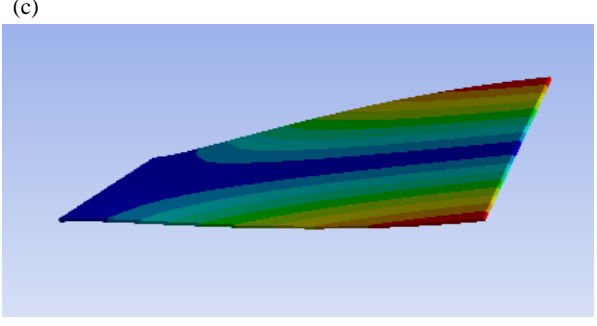

Fig. 8: First three modes for both plates; a) 1st mode bending; b) 2nd mode bending and c) 3rd mode twisting

\section{CONCLUSION}

This paper studies the vibration behavior of the elastic cantilever plate under pre-stresses. Three types of pre-stresses are studies, pre-stress due to gravity, side fluid pressure and direct tensile and compressive forces. For the gravity effect, the cantilever plate supported with different angle started from vertical downward and ended to vertical upward. For side fluid pressure effect, the cantilever plate supported vertically downward in different immersed ratios in water. And for direct tensile and compressive forces effect, direct forces applied at the tip and parallel to the plate axis with different values. For all cases, the first three natural frequencies and mode shapes of the cantilever plate were investigated. Some of the conclusions can be summarized as follows. 
There are clear effects of the pre-stressed on the cantilever plate natural frequencies, especially on the low natural frequencies and bending modes where in some cases in torsion mode the natural frequency still constant during some changing interval. For all cases studied in this study, the natural frequencies were changed under the effect of the pre-stresses but the mode shapes still the same with and without the pre-stresses effect.

In order to take the gravity effect into account in the modal analysis of cantilever plate, the effect of pure tensile and pure compressive stresses is approximately closed. It is found that the pure tensile increased the first three natural frequencies and the pure compressive decreased the first three naturals. Where in the case of pure compressive the plate tends to buckle which cause to vibrate the plate early in frequency less than that without stress. In the case of pure bending, i.e., the tensile in the outer layer and compressive in the inner layer of the plate are equal, the frequencies still constant with and without the gravity effect. In bending behavior, if the tensile on the outer layer is more than the compressive in the inner layer of the plate, the frequencies were increased and vice versa is true.

It is found that the immersed in fluid decrease the natural frequencies, especially for the low frequency with increasing the immersed ratio. The effect of immersed in fluid change the torsion frequency more than the bending frequency. The direct force changes the frequencies. The direct tensile force (tensile stress) increasing the frequencies and the direct compressive force (compressive stress) decreasing the frequencies, especially in low frequencies and bending modes. The effect of direct compressive is more than the direct tensile stress where the compressive stress tends to buckle the plate which causing to vibrate the plate early. For all pre-stresses cases, the mode shapes still the same with and without pre-stresses.

\section{REFERENCES}

Abramovich, H., 1992. Natural frequencies of Timoshenko beams under compressive axial loads. J. Sound Vibr., 157: 183-189.

Abramovich, H., 1993. Free vibrations of gravity loaded composite beams. Compos. Struct., 23: 17-26.

Bokaian, A., 1988. Natural frequencies of beams under compressive axial loads. J. S ound Vibr., 126: $49-65$.

Bokaian, A., 1990. Natural frequencies of beams under tensile axial loads. J. Sound Vibr., 142: 481-498.

Cornil, M.B., L. Capolungo, J. Qu and V.A. Jairazbhoy, 2007. Free vibration of a beam subjected to large static deflection. J. Sound Vibr., 303: 723-740.

Lajimi, S.A.M. and G.R. Heppler, 2012. Comments on natural frequencies of a uniform cantilever beam with a tip mass slender in the axial direction. J. Sound Vibr., 331: 2964-2968.

Leissa, A.W., 1969. Vibration of Plates. Scientific and Technical Information Division, National Aeronautics and Space Administration, Washington, DC., USA.

Seshu, P., 2012. Textbook of Finite Element Analysis. PHI Learning Private Limited, New Delhi, India, Pages: 330.

Werner, S., 2004. Vibrations of Shells and Plates. 3rd Edn., Marcel Dekker, New York, USA., Pages: 539.

Yokoyama, T., 1990. Vibrations of a hanging Timoshenko beam under gravity. J. Sound Vibr., 141: 245-258. 